\title{
Anterior cervical discectomy and fusion in the outpatient ambulatory surgery setting compared with the inpatient hospital setting: analysis of 1000 consecutive cases
}

\author{
Tim Adamson, MD, ${ }^{2}$ Saniya S. Godil, MD, ${ }^{2}$ Melissa Mehrlich, RN, MHA, CCRP, \\ Stephen Mendenhall, BS, ${ }^{2}$ Anthony L. Asher, MD, ${ }^{1}$ and Matthew J. McGirt, MD1 \\ ${ }^{1}$ Carolina Neurosurgery \& Spine Associates, Charlotte, North Carolina; and ${ }^{2}$ Department of Orthopedics, Vanderbilt University
Medical Center, Nashville, Tennessee
}

\begin{abstract}
OBJECTIVE In an era of escalating health care costs and pressure to improve efficiency and cost of care, ambulatory surgery centers (ASCs) have emerged as lower-cost options for many surgical therapies. Anterior cervical discectomy and fusion (ACDF) is one of the most prevalent spine surgeries performed, and the frequency of its performance is rapidly increasing as the aging population grows. Although ASCs offer significant cost advantages over hospital-based surgical centers, concern over the safety of outpatient ACDF has slowed its adoption. The authors intended to 1) determine the safety of the first 1000 consecutive ACDF surgeries performed in their outpatient ASC, and 2) compare the safety of these outpatient ACDFs with that of consecutive ACDFs performed during the same time period in the hospital setting.
\end{abstract}

METHODS A total of 1000 consecutive patients who underwent ACDF in an ACS (outpatient ACDF) and 484 consecutive patients who underwent ACDF at Vanderbilt University Hospital (inpatient ACDF) from 2006 to 2013 were included in this retrospective study of patients' medical records. Data were collected on patient demographics, comorbidities, operative details, and perioperative and 90-day morbidity. Perioperative morbidity and hospital readmission were compared between the outpatient and inpatient ACDF groups.

RESULTS Of the first 1000 outpatient ACDF cases performed in the authors' ASC, 629 (62.9\%) were 1-level and 365 (36.5\%) were 2-level ACDFs. Mean patient age was $49.5 \pm 8.6$, and $484(48.4 \%)$ were males. All patients were observed postoperatively at the ASC postanesthesia care unit (PACU) for 4 hours before being discharged home. Eight patients $(0.8 \%)$ were transferred from the surgery center to the hospital postoperatively (for pain control [ $n=3]$, chest pain and electrocardiogram changes [ $n=2$ ], intraoperative CSF leak [ $n=1]$, postoperative hematoma [ $n=1]$, and profound postoperative weakness and surgical reexploration $[n=1])$. No perioperative deaths occurred. The 30-day hospital readmission rate was $2.2 \%$. All 90-day surgical morbidity was similar between outpatient and inpatient cohorts for both 1 -level and 2-level ACDFs.

CONCLUSIONS An analysis of 1000 consecutive patients who underwent ACDF in an outpatient setting demonstrates that surgical complications occur at a low rate (1\%) and can be appropriately diagnosed and managed in a 4-hour ASC PACU window. Comparison with an inpatient ACDF surgery cohort demonstrated similar results, highlighting that ACDF can be safely performed in the outpatient ambulatory surgery setting without compromising surgical safety. In an effort to decrease costs of care, surgeons can safely perform 1- and 2-level ACDFs in an ASC environment.

http://thejns.org/doi/abs/10.3171/2015.8.SPINE14284

KEY WORDS outpatient surgery; anterior cervical discectomy and fusion; safety

$\mathrm{S}$ INCE Smith and Robinson ${ }^{21}$ and Cloward ${ }^{4}$ first described the procedure in 1958, anterior cervical discectomy and fusion (ACDF) has become one of the most commonly performed spinal operations. ACDF is considered the gold standard for many degenerative cervi- cal spine diseases due to its relative simplicity, minimal risk, and reliability. ${ }^{7}$ From 1990 to 2000, the total number of cervical spine procedures performed annually more than doubled, from 53,810 to $112,400 .{ }^{15}$ In fact, more ACDFs were performed from 1999 to 2004 than during

ABBREVIATIONS ACDF = anterior cervical discectomy and fusion; ASA = American Society of Anesthesiologists; $A S C=$ ambulatory surgery center; BMI = body mass index; CCSS = Carolina Center for Specialty Surgery; EBL = estimated blood loss; EKG = electrocardiogram; PACU = postanesthesia care unit; SSI = surgical site infection. SUBMITTED March 18, 2014. ACCEPTED August 11, 2015.

INCLUDE WHEN CITING Published online February 5, 2016; DOI: 10.3171/2015.8.SPINE14284. 
the entire previous decade..$^{12}$ The prevalence of ACDF has risen steadily, with the rates of cervical fusion in the elderly rising 206\% from 1992 to 2005 among Medicare beneficiaries. ${ }^{23}$

Critical examination of the increasing application of surgical procedures such as ACDF is particularly relevant at a time when nearly $18 \%$ of the US gross domestic product is devoted to health care expenditures, with the cost of surgical care alone comprising $7 \%$ of the gross domestic product. ${ }^{23}$ In this era of escalating health care costs and universal pressure to improve the efficiency of care, the focus of all stakeholders has shifted to improving efficiency. In a surgical context, this translates to cost containment by reducing the number of hospital days, perioperative morbidity, and postsurgical hospital readmission. An increasingly popular cost-saving strategy has involved a shift in medical procedures to outpatient and ambulatory surgery centers (ASCs). Technological advances and improvement in anesthesia and surgical techniques now allow numerous surgical procedures to be performed on an outpatient basis. Annual cost savings of up to $\$ 140$ million have been reported in the literature with the utilization of ASCs for spine surgery. ${ }^{19}$ Outpatient surgeries are not only a costeffective option, they also offer the theoretical benefit of a reduction in nosocomial risks and medical errors associated with the inpatient hospital setting ${ }^{9}$ and have been shown by some investigators to be associated with more rapid recovery and higher patient satisfaction after surgery. ${ }^{6,8,10,18}$

Evidence is growing that supports the safety and effectiveness of ASCs for lumbar decompression and discectomy; however, evidence for the safety and value of outpatient ACDF remains scarce. ${ }^{1-3,16,20,25}$ Although short-term costs to health care providers, third-party payers, and health care purchasers tend to be lower in ASCs, cost savings will only be realized across the entire outpatient care episode if that care is associated with surgical safety on par with safety in inpatient settings. Cheaper surgical care up front will lose its value if associated with decreased safety and elevated downstream costs of complications and readmissions. Accordingly, demonstration of equivalent surgical safety is necessary to determine the relative value of outpatient versus inpatient ACDF.

In light of these considerations, we set out to 1) determine the safety of 1000 consecutive ACDF surgeries performed in an outpatient ambulatory surgery setting, and 2) compare the safety of outpatient ACDF with consecutive inpatient ACDF surgeries performed during the same time period.

\section{Methods}

After approval from the Carolina's Healthcare System institutional review board, the medical records of 1000 consecutive patients who underwent ACDF from 2006 to 2013 at the Carolina Center for Specialty Surgery (CCSS) ambulatory surgery center (outpatient ACDF) were retrospectively analyzed. Data related to patient demographics, comorbidities, operative details, and perioperative and 90day morbidity were included in the study.

A total of 484 consecutive patients (American Society of Anaesthesiologists [ASA] Class I or II) who underwent
ACDF from 2006 to 2013 at Vanderbilt University Hospital (inpatient ACDF) were also included in the study. Data were collected on patient demographics, comorbidities, operative details, and perioperative and 90-day morbidity. Perioperative morbidity and 90-day readmission/reoperation were compared between the outpatient and inpatient ACDF groups. Perioperative and 90-day morbidity were compared separately for 1-level and 2-level ACDF in the outpatient versus the inpatient setting.

\section{Statistical Analysis}

All statistical analyses were performed using STATA (version 12.0, StataCorp). Parametric data are provided as means \pm standard deviations and were compared using the Student t-test. Nonparametric data are provided as medians (interquartile range) and were compared using the Mann-Whitney U-test. Nominal data were compared via the chi-square test. A $\mathrm{p}$ value $<0.05$ was considered statistically significant.

\section{Results \\ Outpatient ACDF}

A total of 1000 outpatient ACDF cases performed from 2006 to 2013 were included in the study. The mean age of the patients was $49.5 \pm 8.6$ years, and $484(48.4 \%)$ were males. Baseline characteristics and patient demographics are presented in Table 1. A majority of the patients were ASA Class I (19.5\%) or II (74.1\%). The most common comorbidities in this patient population were depression $(15.3 \%)$ and diabetes $(8.3 \%)$. The mean body mass index (BMI) of patients was $28.5 \pm 5.4$. Most patients underwent primary ACDF (91.6\%), and only $8.4 \%$ underwent revision ACDF.

A total of 629 patients $(62.9 \%)$ underwent 1-level ACDF and 365 (36.5\%) underwent 2-level ACDF (Table 2). Mean estimated blood loss (EBL) was $43.4 \pm 24.3 \mathrm{ml}$, and mean length of surgery was $73.3 \pm 24.5 \mathrm{~min}$. All patients were

TABLE 1. Baseline characteristics and patient demographics of 1000 consecutive patients undergoing outpatient ACDF

\begin{tabular}{cc}
\hline Demographics and Comorbidities & Outpatient ACDF (\%) \\
\hline Mean age \pm SD & $49.5 \pm 8.6$ \\
\hline Males & $484(48.4)$ \\
\hline ASA Class & \\
1 & $195(19.5)$ \\
2 & $741(74.1)$ \\
3 & $64(6.4)$ \\
4 & $0(0.0)$ \\
\hline CAD & $22(2.2)$ \\
\hline COPD & $8(0.8)$ \\
\hline DM & $83(8.3)$ \\
\hline Osteoporosis & $17(1.7)$ \\
\hline Depression & $153(15.3)$ \\
\hline Mean BMI \pm SD & $28.5 \pm 5.4$ \\
\hline Revision surgery & $84(8.4)$ \\
\hline
\end{tabular}

$\mathrm{CAD}=$ coronary artery disease; $\mathrm{COPD}=$ chronic obstructive pulmonary disease; $\mathrm{DM}=$ diabetes mellitus. 
TABLE 2. Surgical variables and 90 -day morbidity in 1000 patients undergoing outpatient ACDF

\begin{tabular}{lc}
\hline \multicolumn{1}{c}{ Variable } & Outpatient ACDF $(\%)$ \\
\hline No. of Levels & $629(62.9)$ \\
1 & $365(36.5)$ \\
2 & $6(0.6)$ \\
\hline$>2$ & $43.4 \pm 24.3$ \\
\hline Mean EBL \pm SD $(\mathrm{ml})$ & $73.3 \pm 24.5$ \\
\hline Mean length of surgery \pm SD (min) & $0.02 \pm 0.4$ \\
\hline Mean length of hospital stay \pm SD (days) & $8(0.8)$ \\
\hline Transferred from outpatient to inpatient & $22(2.2)$ \\
\hline 30 -day readmission & $11(1.1)$ \\
\hline 30 - to 90-day readmission & $2(0.2)$ \\
\hline 90-day reoperation (same site) & \\
\hline Reason for reoperation & $0(0.0)$ \\
\hline Hardware failure & $2(0.2)$ \\
\hline Hematoma evacuation & $0(0.0)$ \\
\hline Esophageal perforation & $0(0.0)$ \\
\hline CSF leak & $0(0.0)$ \\
\hline Progressive worsening of symptoms & $14(1.4)$ \\
\hline Dysphagia & $2(0.2)$ \\
\hline SSI & $2(0.2)$ \\
\hline Neck hematoma & $0(0.0)$ \\
\hline Carotid injury & $0(0.0)$ \\
\hline Esophageal perforation & $0(0.0)$ \\
\hline New spinal cord deficit & $2(0.2)$ \\
\hline New nerve root deficit & $1(0.1)$ \\
\hline Deaths & \\
\hline
\end{tabular}

observed postoperatively in the outpatient surgery center for 4 hours before being discharged home. Eight patients $(0.8 \%)$ were transferred from the surgery center to the hospital postoperatively; 3 patients were transferred for pain control, 2 had chest pain and electrocardiogram (EKG) changes, 1 had intraoperative CSF leak, 1 had postoperative hematoma, and 1 had profound postoperative weakness and underwent surgical reexploration.

All 90-day morbidities are presented in Table 2. A total of 22 patients $(2.2 \%)$ had 30-day readmissions, and 11 $(1.1 \%)$ were readmitted between 30 and 90 days after surgery. Two patients $(2.2 \%)$ underwent reoperation for hematoma evacuation; 1 was directly transferred from the outpatient center to the hospital and the other presented to the emergency department later the same day with respiratory problems and was taken to the operating room for hematoma evacuation within 24 hours of the primary surgery. Dysphagia requiring an alteration in diet was noted in 14 patients $(1.4 \%)$, whereas $2(0.2 \%)$ had surgical-site infection (SSI) requiring intravenous antibiotics or surgical debridement, or both, and $2(0.2 \%)$ had new nerve root deficit postoperatively.

\section{Comparison of Outpatient Versus Inpatient ACDF}

A total of 484 inpatient ACDF surgeries were performed on patients with ASA Class I and II from 20062013. One-level ACDF was performed in 274 patients
(56.6\%), and 2-level ACDF was performed in 210 patients $(43.4 \%)$. There were no significant differences in the baseline characteristics and comorbidities between those who were outpatient versus those who were inpatient except age, which was significantly higher in the outpatient cohort (Tables 3 and 4).

\section{Perioperative Safety and 90-Day Morbidity}

The length of hospital stay was significantly higher in the inpatient compared with the outpatient cohort. Estimated blood loss and length of surgery were slightly greater in the inpatient cohort but were not clinically significant. All 90-day surgical morbidity was similar between outpatient and inpatient cohorts for 1-level ACDF, including 30-day readmission $(1.8 \%$ vs $2.9 \%$; $p=0.24), 90$-day readmission $(1.3 \%$ vs $1.5 \% ; \mathrm{p}=0.80), 90$-day reoperation $(0.2 \%$ vs $0.4 \% ; \mathrm{p}=0.54)$, SSI $(0.2 \%$ vs $0.0 \% ; \mathrm{p}=0.51)$, neck hematoma $(0.2 \%$ vs $0.4 \% ; \mathrm{p}=0.54)$, and new nerve root deficit $(0.2 \%$ vs $0.0 \% ; p=0.51$; Table 3$)$. Similarly, all 90 day surgical morbidity was similar between outpatient and inpatient cohorts for 2-level ACDF (Table 4). Interestingly, dysphagia requiring an alteration in diet occurred at a very low rate, but the rate was slightly higher $(1.8 \%$ vs $0.0 \%$; $=0.03$ ) in the outpatient 1-level cohort. One patient died 3 months after ACDF surgery in the ASC from a previously undiagnosed glioblastoma multiform. There was no ACDF-related mortality within 90 days of surgery.

\section{Discussion}

Over the more than 50 years that $\mathrm{ACDF}$ has been used for the management of cervical spondylotic disease, the procedure has evolved substantially. For decades, the standard technique involved harvesting autograft from a second site, usually the anterior iliac crest. The availability of reliable and safe allograft sources and the development of biologically inert structural spacers, such as polyaryletherketone, allowed a shift away from the routine use of autograft and its associated pain and morbidity. Over the past 25 years, the development of safe and easily applied anterior fixation with plates has allowed further improvements, especially in patient comfort and recovery in the postoperative period. The goal of solid fusion is now consistently obtained with cervical plating and has eliminated the need for postoperative immobilization with cervical orthoses in most patients. All of these changes have made ACDF a very safe procedure with predictably good results and low rates of morbidity.

Rapidly increasing health care costs have forced care providers and society in general to consider a variety of options to slow or reduce medical expenditures while preserving the safety and effectiveness of therapies. Outpatient surgeries performed in ASCs have already been shown to diminish the cost of some procedures on a caseby-case basis. Our own experience with lumbar laminectomy has shown facility fee savings of $30 \%$ or more from hospital inpatient settings with similar outcomes and complication rates (Parker S, Asher A, Dyer H, et al: Cost effectiveness and comparative effectiveness of outpatient vs. inpatient lumbar discectomy: a prospective, multi-center longitudinal outcomes study. Presentation to the Congress of Neurological Surgeons, Boston, MA, October 2014). 
TABLE 3. Comparison of 1-level outpatient versus inpatient ACDF*

\begin{tabular}{|c|c|c|c|}
\hline Variable & Inpatient ACDF (\%) & Outpatient ACDF (\%) & p Value \\
\hline No. of patients & 274 & 629 & \\
\hline Mean age \pm SD (yrs) & $45.7 \pm 9.5$ & $48.3 \pm 8.8$ & $<0.001$ \\
\hline Males & $143(52.2)$ & $307(48.8)$ & 0.35 \\
\hline CAD & $4(1.5)$ & $15(2.4)$ & 0.37 \\
\hline COPD & $6(2.2)$ & $6(1.0)$ & 0.14 \\
\hline DM & $23(8.4)$ & $57(9.1)$ & 0.75 \\
\hline Osteoporosis & $6(2.2)$ & $14(2.2)$ & 0.97 \\
\hline Depression & $51(18.6)$ & $106(16.9)$ & 0.53 \\
\hline Mean BMI \pm SD & $29.0 \pm 5.7$ & $28.6 \pm 5.3$ & 0.35 \\
\hline Revision surgery & $14(5.1)$ & $58(9.2)$ & 0.04 \\
\hline Mean EBL $\pm \mathrm{SD}(\mathrm{ml})$ & $85.0 \pm 97.5$ & $39.8 \pm 24.8$ & $<0.001$ \\
\hline Mean length of surgery $\pm \mathrm{SD}$ (min) & $197.7 \pm 42.3$ & $65.0 \pm 16.6$ & $<0.001$ \\
\hline Mean length of hospital stay \pm SD (days) & $1.1 \pm 1.7$ & $0.01 \pm 0.11$ & $<0.001$ \\
\hline 30-day readmission & $8(2.9)$ & $11(1.8)$ & 0.24 \\
\hline 90-day readmission & $4(1.5)$ & $8(1.3)$ & 0.80 \\
\hline 90-day reoperation (same site) & $1(0.4)$ & $1(0.2)$ & 0.54 \\
\hline \multicolumn{4}{|l|}{ Reason for reoperation } \\
\hline Hematoma evacuation & $1(0.4)$ & $1(0.2)$ & \\
\hline Dysphagia & $0(0.0)$ & $11(1.8)$ & 0.03 \\
\hline SSI & $0(0.0)$ & $1(0.2)$ & 0.51 \\
\hline Neck hematoma & $1(0.4)$ & $1(0.2)$ & 0.54 \\
\hline Carotid injury & $0(0.0)$ & $0(0.0)$ & 1.00 \\
\hline Esophageal perforation & $0(0.0)$ & $0(0.0)$ & 1.00 \\
\hline New spinal cord deficit & $0(0.0)$ & $0(0.0)$ & 1.00 \\
\hline New nerve root deficit & $0(0.0)$ & $1(0.2)$ & 0.51 \\
\hline Deaths & $0(0.0)$ & $0(0.0)$ & 1.00 \\
\hline
\end{tabular}

Compared with other procedures, ACDF has less rapidly transitioned to the outpatient setting, possibly for concern with some of the potential risks unique to the anterior cervical exposure. Although these complications, such as neck hematoma and airway compromise, are concerning, their occurrence is very rare as reported here. Because of the low incidence of these high-impact complications, small surgical series (e.g., 60-100 patients) have limited capability to accurately define the potential consequence of outpatient ACDF. These previously published studies examining complication rates in less than 100 outpatient ACDFs (Erickson et al., ${ }^{6}$ Liu et al., ${ }^{11}$ and Trahan et al. ${ }^{22}$ ) were not appropriately powered to make meaningful conclusions about complications that are expected to occur in the inpatient setting at a rate of $2 \%-5 \%$.

To date, there have been no reports of at least several hundred patients treated with ACDF in the outpatient setting. Therefore, a substantial knowledge gap exists with respect to this emerging treatment paradigm. Unless large-volume programs share their experience with outpatient procedures such as ACDF, surgeons, patients, hospital systems, third-party payers, and policy makers will lack evidence needed to make decisions about the safety of less-costly outpatient ACDF. The experience with 1000 consecutive outpatient ACDF cases reported here reinforces and strengthens conclusions about the safety and efficacy of this therapy previously reported in smaller series, and has the potential to more appropriately inform the clinical and systems-based decision-making processes of patients, surgeons, hospital systems, or payers considering the ASC setting for ACDF surgery.

Our initial experience with outpatient ACDFs was limited to select patients who were believed to be at lowest risk for perioperative complications. That experience was then expanded to more complicated situations (such as 2-level procedures when the patient was believed to be a candidate for the outpatient setting). We chose a 4-hour interval in which to monitor patients before discharge based on an internal face-validation process (i.e., participating surgeons were asked to review their own postoperative complications, and at what point they had occurred; most felt that such problems tended to occur within a 4-hour window).

The inpatient hospital group and the ASC group were found to be very similar in all aspects that were compared (Tables 3 and 4). Not all patients are appropriate for the outpatient surgery setting; assignment to the outpatient setting is typically made cooperatively by the involved anesthesiologist and surgeon. Because ASC patients tend to 
TABLE 4. Comparison of 2-level outpatient versus inpatient ACDF*

\begin{tabular}{|c|c|c|c|}
\hline Variable & Inpatient ACDF (\%) & Outpatient ACDF (\%) & $\mathrm{p}$ Value \\
\hline No. of patients & 210 & 365 & \\
\hline Mean age \pm SD (yrs) & $47.9 \pm 8.6$ & $51.4 \pm 7.8$ & $<0.001$ \\
\hline Males & $89(42.4)$ & $171(46.9)$ & 0.30 \\
\hline CAD & $2(1.0)$ & $6(1.6)$ & 0.50 \\
\hline COPD & $1(0.5)$ & $2(0.6)$ & 0.90 \\
\hline $\mathrm{DM}$ & $22(10.5)$ & $26(7.1)$ & 0.16 \\
\hline Osteoporosis & $8(3.8)$ & $3(0.8)$ & 0.01 \\
\hline Depression & $54(25.7)$ & $47(12.9)$ & $<0.001$ \\
\hline Mean BMI \pm SD & $29.3 \pm 6.2$ & $28.3 \pm 5.6$ & 0.07 \\
\hline Revision surgery & $27(12.9)$ & $26(7.1)$ & 0.02 \\
\hline Mean EBL \pm SD (ml) & $116.0 \pm 103.8$ & $48.1 \pm 22.0$ & $<0.001$ \\
\hline Mean length of surgery \pm SD (min) & $240.5 \pm 53.0$ & $86.1 \pm 22.8$ & $<0.001$ \\
\hline Mean length of hospital stay \pm SD (days) & $1.1 \pm 0.8$ & $0.03 \pm 0.6$ & $<0.001$ \\
\hline 30-day readmission & $8(3.8)$ & $11(3.0)$ & 0.60 \\
\hline 90-day readmission & $1(0.5)$ & $3(0.8)$ & 0.63 \\
\hline 90-day reoperation (same site) & $1(0.5)$ & $1(0.3)$ & 0.69 \\
\hline \multicolumn{4}{|l|}{ Reason for reoperation } \\
\hline Hematoma evacuation & $0(0.0)$ & $1(0.3)$ & \\
\hline CSF leak & $1(0.5)$ & $0(0.0)$ & \\
\hline Dysphagia & $2(1.0)$ & $3(0.8)$ & 0.87 \\
\hline SSI & $0(0.0)$ & $1(0.3)$ & 0.45 \\
\hline Neck hematoma & $0(0.0)$ & $1(0.3)$ & 0.45 \\
\hline Carotid injury & $0(0.0)$ & $0(0.0)$ & 1.00 \\
\hline Esophageal perforation & $1(0.5)$ & $0(0.0)$ & 0.19 \\
\hline New spinal cord deficit & $0(0.0)$ & $0(0.0)$ & 1.00 \\
\hline New nerve root deficit & $2(1.0)$ & $1(0.3)$ & 0.27 \\
\hline Deaths & $0(0.0)$ & $1(0.3)$ & 0.45 \\
\hline
\end{tabular}

* Estimated blood loss, length of surgery, and length of hospital stay were significantly higher in the inpatient compared with the outpatient cohort. All 90-day surgical morbidity was similar between outpatient and inpatient cohorts.

have few comorbidities, the inpatient cohort was limited to only patients with ASA Class I or II; however, it should be noted that select patients with ASA Class III were operated on in the ASC setting (6.4\%). Comorbidities were very similar in the 2 groups, although the ASC group was slightly older on average. The inpatient cohort setting did include residents. This difference likely explains the slightly longer operative time and increased blood loss observed. While these slight differences in EBL and operative time were statistically significant, it is unlikely that they are clinically significant.

Surgical complication rates in both groups confirm the overall safety of the ACDF procedure. Transient radicular deficits and dysphagia were less than $2 \%$. More rare but more serious occurrences, such as hematoma and vascular and esophageal injury, were all less than $0.5 \%$. Hospital readmission within 30 or 90 days was similar between the 2 groups, and the 90 -day reoperation rate was $0.5 \%$ or lower for both.

In total, $8 \mathrm{ASC}$ patients $(0.08 \%)$ were transferred to a hospital setting from the PACU. Pain control was the main issue in 3 of these patients, 2 patients had EKG changes with chest pain, 1 had a dural tear, 1 a hematoma, and 1 declining neurological status. Seven of the 8 patients were monitored overnight and discharged home the following morning without any specific intervention.

In both groups, 2 patients required reoperation at the same site within 90 days. In the ASC patients, both of these occurred in the first 24 hours. The first patient experienced a slowly enlarging hematoma in the anterior neck that progressively interfered with swallowing but did not compromise the airway. This patient was admitted to the hospital after an office evaluation on postoperative Day 1, and the hematoma was evacuated later that day. The dysphagia improved quickly, and the patient was discharged home the following day without long-term difficulty.

The second patient underwent an uneventful 2-level ACDF for myelopathy and was almost 4 hours postoperative when she developed a right hemiparesis. She was transferred to the nearby hospital, and due to rapid progression of the deficit it was elected to take the patient urgently to the operating room for neck exploration and evacuation of a presumed hematoma. No hematoma was found during the procedure, however. In the PACU, the patient was found to have facial weakness in addition to her hemiparesis. Subsequent cranial imaging revealed an 
acute intracerebral hematoma, which was later found to be due to a previously undiagnosed glioblastoma.

Other than the 1 patient who hemorrhaged into a preexisting, previously undiagnosed glioblastoma, all 7 of the other patients requiring transfer to the hospital experienced no long-term consequences. No myocardial infarction was detected in the 2 patients with EKG changes, no consequence of durotomy was noted after a 48-hour observation, and acute pain was resolved with intravenous narcotics and observation for 48 hours for the 3 patients with severe postoperative neck pain. The single patient requiring neck hematoma evacuation suffered no lingering consequences once discharged after revision surgery on postoperative Day 2.

Interestingly, dysphagia that required an alteration in diet occurred at a very low rate, but was slightly higher (n $=11,1.8 \%$ vs $0.0 \%$, respectively; $\mathrm{p}=0.03$ ) in the outpatient 1 -level cohort. In these 11 outpatients, a mechanical soft diet was recommended, and a Solu-Medrol dose pack was often administered. All patients' dysphagia resolved by 2 weeks after surgery. It is unclear why this small difference in dysphagia was observed. It may be that chart documentation differed between care settings, or it was surgeon related. Similar to the slight differences in blood loss and operative time in favor of ASC, the $2 \%$ difference of dysphagia in favor of the inpatient setting may not be clinically significant. The outcomes measured here were largely equivalent with no clear advantage in safety in either operative setting.

Three previous series have demonstrated the feasibility of outpatient ACDF. Erickson et al. in 2007 reported that 56 patients successfully underwent outpatient ACDF without complication and reported a $95 \%$ satisfaction rate. ${ }^{6}$ Liu et al. in 2009 reported on 45 outpatient versus 64 inpatient ACDF surgeries. Similarly, these authors reported no complications in the outpatient setting compared with 4 in the inpatient setting. There was no difference in patients reporting "excellent" outcome between groups. ${ }^{11}$ Lastly, Trahan et al. in 2011 reported a similar complication rate in 59 outpatient versus 68 inpatient ACDFs. Only 1 patient who underwent ACDF as an outpatient experienced a complication, which was described as neck swelling requiring hospital admission for observation. ${ }^{22}$ While these initial studies could describe the feasibility of performing $\mathrm{ACDF}$ in an ASC setting, none provide the statistical power to assess complications that occur only once or twice per 100 cases. Physicians or health care systems, or both, considering adopting ACDF in the ASC setting need robust evidence to adequately assess the risks of this treatment paradigm. Hence, larger series and experiences, such as ours, are needed for researchers to begin to understand the true safety of outpatient ACDF.

Although the aim of this study was not to measure cost savings of ACDF in the ASC setting, much evidence exists on cost savings associated with outpatient spine surgery. ${ }^{2,13,19,24}$ On average, our outpatient surgery center facility fees are roughly $70 \%$ of the fees for the in-hospital setting. Savings will vary greatly market to market, and costs often remain proprietary. Nevertheless, ASCs have yet to prove more costly for any surgical disease state. ${ }^{5,14,19}$ In addition to potential cost savings, other theoretical ad- vantages exist with outpatient ACDF. Wait times are shorter and administrative procedures are often streamlined in ASC settings. Many centers strive to create a more patient-focused experience, and patient satisfaction has been found to be very high with outpatient ACDF in a previous small series. ${ }^{6}$ ASCs may also provide greater operational efficiency versus the hospital setting.

In the settings where surgeons have equity interests in ASCs, it is important for patients to be informed of this potential conflict of interest in the preoperative consent process. In the case of the ASC examined here, patients are informed regarding any financial interest their surgeons may have and are given the option of surgery in either the inpatient or ASC setting. Given that many studies have proved ASCs produce cost savings with equivalent safety compared with hospitals, any perceived conflict of interest related to the financial relationship of physicians to ASCs must be considered in light of the confluence of interest among stakeholders created by such efficiencies. ${ }^{1,6,11,16,22}$

Our initial experience with 1- and 2-level outpatient ACDF surgery in patients with ASA Class I and Class II provided experience and evidence to support the adoption of outpatient ACDF only under specific parameters. Presently, patients who may require conversion to corpectomy due to ossification of the posterior longitudinal ligament or migrated disc fragments, those who require revision $\mathrm{ACDF}$ and neck dissection through scar tissue, or those with comorbidities related to altered airway or neck anatomy are not considered for outpatient ACDF regardless of ASA classification. The ASC examined here does not allow ACDF surgery after noon, to allow for a full 4 hours of PACU monitoring and controlled transfer to the hospital setting during normal working hours in the event that a complication occurs. Furthermore, the CCSS ASC is directly across the street from its parent hospital system, allowing very timely transfer if needed. The safety reported here might not be reproducible in ASCs performing ACDF in patients with higher medical or anatomical risks, in ASCs located at a lengthy distance from a hospital environment, with surgeons infrequently performing ACDF, or in settings without at least a 4-hour PACU monitoring capability. With these exclusions, however, we have demonstrated in a large experience of 1000 patients that ACDFs can be safely performed in an ASC with a risk profile similar to that of the inpatient hospital setting. We believe that this analysis adds substantially to the existing literature, because previous studies have not provided the power to accurately assess the incidence or impact of ACDF complications occurring in the ASC environment.

\section{Conclusions}

ACDF can be performed in the ASC environment with equivalent safety compared with safety in the inpatient hospital setting. As with any health care setting, it is important to have contingency plans in place for possible emergency situations even though they may occur at a frequency of 1 in 1000 events. Not all patients are candidates for procedures in the ASC setting, and selection criteria determined by the surgical and anesthesia teams are important. However, in appropriate patients, ACDFs 
performed in the outpatient setting appear to be as safe as those performed in the inpatient hospital setting and potentially accomplished at a much lower cost. Future studies are needed to formally compare the overall quality or cost-utility of care between these 2 operative care settings.

\section{Acknowledgments}

We want to acknowledge Elizabeth Spivey and Kristi Rose for their help in data collection.

\section{References}

1. Best NM, Sasso RC: Success and safety in outpatient microlumbar discectomy. J Spinal Disord Tech 19:334-337, 2006

2. Bookwalter JW III, Busch MD, Nicely D: Ambulatory surgery is safe and effective in radicular disc disease. Spine (Phila Pa 1976) 19:526-530, 1994

3. Cares HL, Steinberg RS, Robertson ET, Caldini P: Ambulatory microsurgery for ruptured lumbar discs: report of ten cases. Neurosurgery 22:523-526, 1988

4. Cloward RB: The anterior approach for removal of ruptured cervical disks. J Neurosurg 15:602-617, 1958

5. Colegate-Stone T, Roslee C, Shetty S, Compson J, Sinha J, Tavakkolizadeh A: Audit of trauma case load suitable for a day surgery trauma list and cost analysis. Surgeon 9:241244,2011

6. Erickson M, Fites BS, Thieken MT, McGee AW: Outpatient anterior cervical discectomy and fusion. Am J Orthop 36:429-432, 2007

7. Fowler SB, Anthony-Phillips P, Mehta D, Liebman K: Health-related quality of life in patients undergoing anterior cervical discectomy fusion. J Neurosci Nurs 37:97-100, 2005

8. Hersht M, Massicotte EM, Bernstein M: Patient satisfaction with outpatient lumbar microsurgical discectomy: a qualitative study. Can J Surg 50:445-449, 2007

9. Kohn LT, Corrigan JM, Donaldson MS (eds): To Err is Human: Building a Safer Health System. Washington, DC: National Academies Press, 1999

10. Lied B, Rønning PA, Halvorsen CM, Ekseth K, Helseth E: Outpatient anterior cervical discectomy and fusion for cervical disk disease: a prospective consecutive series of $96 \mathrm{pa}-$ tients. Acta Neurol Scand 127:31-37, 2013

11. Liu JT, Briner RP, Friedman JA: Comparison of inpatient vs. outpatient anterior cervical discectomy and fusion: a retrospective case series. BMC Surg 9:3, 2009

12. Marawar S, Girardi FP, Sama AA, Ma Y, Gaber-Baylis LK, Besculides MC, et al: National trends in anterior cervical fusion procedures. Spine (Phila Pa 1976) 35:1454-1459, 2010

13. Mathias JM: Spine surgery migrates to outpatient setting. OR Manager 23:25-27, 2007

14. Mohammad WM, Frost I, Moonje V: Outpatient laparoscopic adrenalectomy: a Canadian experience. Surg Laparosc Endosc Percutan Tech 19:336-337, 2009

15. Patil PG, Turner DA, Pietrobon R: National trends in surgical procedures for degenerative cervical spine disease: 19902000. Neurosurgery 57:753-758, 2005

16. Pugely AJ, Martin CT, Gao Y, Mendoza-Lattes SA: Outpatient surgery reduces short-term complications in lumbar discectomy: an analysis of 4310 patients from the ACS-NSQIP database. Spine (Phila Pa 1976) 38:264-271, 2013

17. Rosen MJ, Malm JA, Tarnoff M, Zuccala K, Ponsky JL: Cost-effectiveness of ambulatory laparoscopic cholecystectomy. Surg Laparosc Endosc Percutan Tech 11:182-184, 2001

18. Sheperd CS, Young WF: Instrumented outpatient anterior cervical discectomy and fusion: is it safe? Int Surg 97:8689,2012

19. Silvers HR, Lewis PJ, Suddaby LS, Asch HL, Clabeaux DE, Blumenson LE: Day surgery for cervical microdiscectomy: is it safe and effective? J Spinal Disord 9:287-293, 1996

20. Singhal A, Bernstein M: Outpatient lumbar microdiscectomy: a prospective study in 122 patients. Can J Neurol Sci 29:249-252, 2002

21. Smith GW, Robinson RA: The treatment of certain cervicalspine disorders by anterior removal of the intervertebral disc and interbody fusion. J Bone Joint Surg Am 40-A:607-624, 1958

22. Trahan J, Abramova MV, Richter EO, Steck JC: Feasibility of anterior cervical discectomy and fusion as an outpatient procedure. World Neurosurg 75:145-148, 43-44, 2011

23. Wang MC, Kreuter W, Wolfla CE, Maiman DJ, Deyo RA: Trends and variations in cervical spine surgery in the United States: Medicare beneficiaries, 1992 to 2005. Spine (Phila Pa 1976) 34:955-963, 2009

24. Wohns R: Safety and cost-effectiveness of outpatient cervical disc arthroplasty. Surg Neurol Int 1:77, 2010

25. Zahrawi F: Microlumbar discectomy. Is it safe as an outpatient procedure? Spine (Phila Pa 1976) 19:1070-1074, 1994

\section{Disclosures}

Tim Adamson and Anthony Asher have a minority equity interest in the Carolina Center for Specialty Surgery.

\section{Author Contributions}

Conception and design: McGirt, Adamson, Asher. Acquisition of data: Godil, Mehrlich, Mendenhall. Analysis and interpretation of data: McGirt, Godil, Mehrlich, Mendenhall. Drafting the article: Adamson, Godil, Mehrlich, Mendenhall. Critically revising the article: McGirt, Adamson, Godil, Asher. Reviewed submitted version of manuscript: McGirt, Adamson, Asher. Approved the final version of the manuscript on behalf of all authors: McGirt. Statistical analysis: Adamson, Godil. Administrative/technical/ material support: McGirt. Study supervision: McGirt, Asher.

\section{Correspondence}

Matthew J. McGirt, Carolina Neurosurgery \& Spine Associates, 225 Baldwin Ave., Charlotte, NC 28204. email: matt.mcgirt@ cnsa.com. 